\title{
Proton transfer or hemibonding? The structure and stability of radical cation clusters
}

\author{
Hainam Do and Nicholas A. Besley* \\ School of Chemistry, University of Nottingham, University Park, \\ Nottingham, NG7 2RD, UK. \\ E-mail: nick.besley@nottingham.ac.uk
}




\begin{abstract}
The basin hopping search algorithm in conjunction with second-order Møller-Plesset perturbation theory is used to determine the lowest energy structures of the radical cation clusters $\left(\mathrm{NH}_{3}\right)_{\mathrm{n}}{ }^{\cdot+},\left(\mathrm{H}_{2} \mathrm{O}\right)_{\mathrm{n}}{ }^{+},(\mathrm{HF})_{\mathrm{n}}{ }^{+},\left(\mathrm{PH}_{3}\right)_{\mathrm{n}}{ }^{+},\left(\mathrm{H}_{2} \mathrm{~S}\right)_{\mathrm{n}}{ }^{+}$and $(\mathrm{HCl})_{\mathrm{n}}{ }^{+}$, where $\mathrm{n}=2-4$. The energies of the most stable structures are subsequently evaluated using coupled cluster theory in conjunction with the aug-cc-pVTZ basis set. These cationic clusters can adopt two distinct structural types, with some clusters showing an unusual type of bonding, often referred to as hemibonding, while other clusters undergo proton transfer to give an ion and radical. It is found that proton transfer based structures are preferred by the $\left(\mathrm{NH}_{3}\right)_{\mathrm{n}}{ }^{{ }^{+}},\left(\mathrm{H}_{2} \mathrm{O}\right)_{\mathrm{n}}{ }^{{ }^{+}}$, and $(\mathrm{HF})_{\mathrm{n}}{ }^{+}$clusters while hemibonded structures are favoured by $\left(\mathrm{PH}_{3}\right)_{\mathrm{n}}{ }^{+},\left(\mathrm{H}_{2} \mathrm{~S}\right)_{\mathrm{n}}{ }^{+}$and $(\mathrm{HCl})_{\mathrm{n}}{ }^{+}$. These trends can be attributed to the relative strengths of the molecules and molecular cations as Brønsted bases and acids, respectively, and the strength of the interaction between the ion and radical in the ion-radical clusters.
\end{abstract}




\section{Introduction}

The properties of ionized clusters can vary significantly from their neutral counterparts and their chemistry has been the subject of many experimental and theoretical studies. ${ }^{1-30}$ One intriguing phenomenon is the formation of 2-center 3electron bonds between the heavy atoms in cationic clusters of molecules such as water and hydrogen sulphide. This bonding is often referred to as hemibonding and can be qualitatively described as a 2-center 3-electron interaction with a formal bond order of $1 / 2$, and occurs when the bonding $\sigma$ molecular orbital between two atoms in a molecular complex is doubly occupied while the complementary antibonding $\sigma^{*}$ orbital is singly occupied. ${ }^{2}$ For radical cationic clusters there is competition to form the lowest energy structure between structures with hemibonding and ion-radical structures resulting from proton transfer. While there has been a large number of studies devoted to study these systems, they have predominantly focused on dimers. ${ }^{2-}$ $11,13-18,20-22,25-27$

The most extensively studied radical cation cluster is $\left(\mathrm{H}_{2} \mathrm{O}\right)_{2}{ }^{+}$, and a wide variety of methods have been applied to characterise its structure. ${ }^{2,5,7,8,10,13-15,17,18,21,25,26}$ The study of $\left(\mathrm{H}_{2} \mathrm{O}\right)_{2}{ }^{+}$has proved to be a challenge for density functional theory (DFT), and many commonly used exchange-correlation functionals wrongly predict the hemibonded structure to be more stable than the proton transfer one. Although, in a recent study that compared a wide range of functionals, it was observed that a longrange corrected double-hybrid functional was more accurate according to several assessment criteria. ${ }^{26}\left(\mathrm{H}_{2} \mathrm{O}\right)_{2}{ }^{+}$has also been studied using wavefunction based approaches such as Møller-Plesset perturbation theory and coupled cluster theory. ${ }^{2,5,7,10,14,15}$ In addition to the water dimer cation, Gill and Radom studied eight dimer cations using second and fourth-order Møller-Plesset perturbation theory (MP2 and MP4) and showed that the first row hydride dimer cations favoured proton transfer structures, while the second row hydride dimers were hemibonded. ${ }^{2}$ Subsequently, more recent studies have considered mixed component dimers and $\left(\mathrm{NH}_{3}\right)_{2}{ }^{+} \cdot 5,6,11,16,27$

There have been only a few studies that go beyond dimers to consider larger 
clusters. These studies include both DFT and coupled cluster theory calculations for the water trimer cation ${ }^{23,29}$ and DFT based calculations for significantly larger water cation clusters. $^{19,28,30}$ One reason for the relative scarcity of theoretical studies of larger clusters compared to dimers is that reliable identification of the lowest energy structures requires a more extensive search through configuration space, and this is compounded by the need to use computationally expensive correlated wavefunction based methods to describe the electronic structure accurately. Recently, we have implemented the Basin Hopping $(\mathrm{BH})^{31}$ global optimization technique within the QChem software package. ${ }^{32,33}$ This implementation facilitates performing a $\mathrm{BH}$ optimisation using quantum chemical methods. This approach has been used to investigate the structure and bonding in ionized water clusters, $\left(\mathrm{H}_{2} \mathrm{O}\right)_{\mathrm{n}}{ }^{{ }^{+}}(\mathrm{n}=3-9),{ }^{30}$ adopting a hierarchical strategy wherein the $\mathrm{BH}$ search was performed using DFT with the structures and energies subsequently refined using MP2 and coupled cluster theory. In this paper, we address the nature of the bonding and structure in the cationic clusters $\left(\mathrm{NH}_{3}\right)_{\mathrm{n}}{ }^{++},\left(\mathrm{H}_{2} \mathrm{O}\right)_{\mathrm{n}}{ }^{+},(\mathrm{HF})_{\mathrm{n}}{ }^{+},\left(\mathrm{PH}_{3}\right)_{\mathrm{n}}{ }^{++},\left(\mathrm{H}_{2} \mathrm{~S}\right)_{\mathrm{n}}{ }^{{ }^{+}}$and $(\mathrm{HCl})_{\mathrm{n}}{ }^{\cdot+}$, where $\mathrm{n}=2-4$, with the aim of determining whether hemibonding or proton transfer based structures are preferred, and subsequently to rationalise the trends observed. The BH technique is used to identify the lowest energy proton-transfer and hemibonded structures, but in contrast to previous studies, the $\mathrm{BH}$ search is performed in conjunction with MP2 rather than DFT. Subsequently, the energies of the clusters are refined using coupled cluster theory calculations.

\section{Computational Details}

The $\mathrm{BH}$ algorithm is a combination of the Metropolis Monte Carlo (MC) sampling technique and a gradient-based local search method, which has the effect of sampling the energy basins instead of sampling configuration space. ${ }^{31}$ The precise details of the $\mathrm{BH}$ implementation used here are described elsewhere, ${ }^{33}$ but briefly we perform a $\mathrm{BH}$ with jumping ${ }^{34}$ search. For each cluster, ten separate runs, consisting of $1000 \mathrm{MC}$ steps starting from different randomly generated configurations of molecules, are performed. A notable difference in the calculations presented here is that the $\mathrm{BH}$ search is performed in conjunction with MP2 applied to an unrestricted Hartree-Fock wavefunction with the $6-31+\mathrm{G}^{*}$ basis set. Subsequently, the relative energies of the low lying clusters are determined using coupled cluster theory with single and double excitations and a perturbative treatment of triple excitations (CCSD(T)) with the aug- 
cc-pVTZ basis set using the MOLPRO software package. ${ }^{35}$ Zero point energies were evaluated from harmonic frequencies calculated using $\mathrm{B} 3 \mathrm{LYP}^{36,37}$ with the empirical dispersion correction of Grimme ${ }^{38}$ in conjunction with the $6-31+\mathrm{G}^{*}$ basis set. The standard values of $s_{6}=1.05$ and $d=20.0$ for B3LYP were used in the dispersion correction. ${ }^{38}$ Prior to the frequency calculations the structure of the clusters were reoptimized at this level of theory but this did not result in a structural change to give a cluster corresponding to a different local minimum.

\section{Results and Discussion}

Figure 1 shows the lowest energy proton-transfer and hemibonded based structures for the six dimers, and the coordinates of structures can be obtained from the Supplementary Information. For the proton-transfer structures the formation of the ion-radical pair can be seen clearly, while in the hemibonded structures the heavy atoms are orientated towards each other, indicative of hemibonding. These structures are consistent with structures identified in previous work. ${ }^{2}$ The structures show that the intermolecular separation between the ion and the radical, and also the length of the hemibond decreases on going across the periodic table. There are a number of different wavefunction analysis techniques that can be applied to illustrate the different nature of the bonding in the two types of cluster. Figure 2 shows the spin density for the $\left(\mathrm{NH}_{3}\right)_{2}{ }^{\cdot+}$ and $(\mathrm{HCl})_{2}{ }^{++}$clusters. For the ion-radical structures, the spin density is localized on the radical $\left(\mathrm{NH}_{2}{ }^{\circ}\right.$ and $\left.\mathrm{Cl}{ }^{\circ}\right)$. However, for the hemibonded structures, the spin density is delocalized equally across the two heavy atoms indicating the presence of the hemibond. Also shown in Figure 2 is the atomic charge of the molecular fragments as given by a Mulliken population analysis. These are consistent with a positively charged ion and neutral fragment in the ion-radical clusters, whereas the positive charge is distributed equally over the two molecular fragments in the hemibonded form.

Figures 3 and 4 show the valence molecular orbitals for the ion-radical and hemibonded $\left(\mathrm{H}_{2} \mathrm{O}\right)_{2}{ }^{\cdot+}$ clusters following the Boys' localization procedure. ${ }^{39}$ The resulting localized orbitals are more chemically intuitive and can be more easily related to the bonding in the clusters. While we focus on the water dimer, the analysis is representative of all the systems studied. For the ion-radical cluster, the singly 
occupied molecular orbital (SOMO) can be identified as a lone pair orbital on $\mathrm{OH}^{\circ}$, with the remaining orbitals corresponding to three $\mathrm{O}-\mathrm{H}$ bonds and one lone pair on $\mathrm{H}_{3} \mathrm{O}^{+}$and one $\mathrm{O}-\mathrm{H}$ bond and a further two lone pairs on $\mathrm{OH}^{\cdot}$. The orbitals for the hemibonded cluster differ significantly. The SOMO can be described as an antibonding $\sigma$ orbital between the two oxygen atoms $\left(\sigma^{*} \mathrm{O}-\mathrm{O}\right)$ while the next orbital is the corresponding bonding combination $\left(\sigma_{\mathrm{O}-\mathrm{O}}\right)$. These orbitals can arise from the inphase and out-of-phase combinations of two lone pair orbitals on the oxygen atoms. The remaining orbitals correspond to two $\mathrm{O}-\mathrm{H}$ bonds and a lone pair on each water molecule. A localized orbital bonding analysis (LOBA) ${ }^{40}$ provides a method to analysis the bonding and determine the oxidation state of atoms within a molecule. For the ion-radical $\left(\mathrm{H}_{2} \mathrm{O}\right)_{2}{ }^{+}$cluster, this shows four O-H bonds, three doubly occupied oxygen lone pair orbitals, one singly occupied lone pair orbital and predicts oxidation states of -1 and -2 for the oxygen atoms. The hemibonded isomer represents a more problematic case for LOBA, but oxygen-oxygen bonding is evident and the analysis suggests an oxidation state of -1.5 for each of the two oxygen atoms. The closely related natural bond orbital analysis shows eight two-centre bonding electrons for the ion-radical form consistent with the four $\mathrm{O}-\mathrm{H}$ bonds. The hemibonded form has nine two-centre bonding electrons. Since there are four O-H bonds, this suggests a bond order of $1 / 2$ for the $\mathrm{O}-\mathrm{O}$ bond.

The relative energies between the two isomer types for each cluster, with and without correcting for zero point energy, are given in Table 1. Initially we will consider the dimers. The results show that for the first row radical cation hydrides the ion-radical structures have the lowest energy, while for the second row radical cation hydrides the hemibonded structures have lower energy. For the sequence $\left(\mathrm{NH}_{3}\right)_{2}{ }^{+} \rightarrow$ $\left(\mathrm{H}_{2} \mathrm{O}\right)_{2}{ }^{{ }^{+}} \rightarrow(\mathrm{HF})_{2}{ }^{{ }^{+}}$the ion-radical isomer becomes increasingly more stable relative to the hemibonded isomer. While for the sequence $\left(\mathrm{PH}_{3}\right)_{2}{ }^{{ }^{+}} \rightarrow\left(\mathrm{H}_{2} \mathrm{~S}\right)_{2}{ }^{{ }^{+}} \rightarrow(\mathrm{HCl})_{2}{ }^{{ }^{+}}$the hemibonded isomer becomes increasingly more stable relative to the ion-radical structure. The inclusion of zero point energy does not alter these trends, but does lower the energy of the ion-radical structures relative to the hemibonded ones. The predicted relative energies are similar to the values reported at the MP4 level. ${ }^{2}$ Although in the results shown here, the hemibonded forms of $\left(\mathrm{H}_{2} \mathrm{~S}\right)_{2}{ }^{++}$and $(\mathrm{HCl})_{2}{ }^{+}$ are predicted to have a greater stability relative to the ion-radical forms. For the cationic water dimer, the ion-radical structure is predicted to be $37.6 \mathrm{~kJ} / \mathrm{mol}$ more stable than the hemibonded form, which agrees well with a value of $38.9 \mathrm{~kJ} / \mathrm{mol}$ 
determined in diffusion Monte Carlo calculations. ${ }^{10}$ Through experiment it has been determined that the energy difference between the radical cationic water dimer and two non associated water molecules lies between $1029 \mathrm{kJmol}^{-1}$ and $1037 \mathrm{kJmol}^{-1}$. From our calculations we find a corresponding value of $1019 \mathrm{kJmol}^{-1}$, which compares well with the value from experiment. Furthermore, the computed $\Delta E_{e}=-21.8$ $\mathrm{kJ} / \mathrm{mol}$ and $\Delta E_{o}=-26.3 \mathrm{~kJ} / \mathrm{mol}$ for $\left(\mathrm{NH}_{3}\right)_{2}{ }^{+}$are close to values of $-21.0 \mathrm{~kJ} / \mathrm{mol}$ and $23.4 \mathrm{~kJ} / \mathrm{mol}$ from complete basis set $\operatorname{CCSD}(\mathrm{T})$ calculations. ${ }^{16}$ The slight discrepancy between the zero point energy corrected values can be attributed to the different methods to evaluate the vibrational frequencies.

A BH search is not necessary to determine the lowest energy structures for the dimers. However, as the cluster becomes larger, the $\mathrm{BH}$ search method becomes a useful approach. The lowest energy structures for the trimers and tetramers are shown in Figures 5 and 6. In the ion-radical structures for the trimers, the ion lies at the centre of the lowest energy isomer with the neutral molecule and radical (hydrogen)bonded to it via its hydrogen atoms. The exception to this is $\left(\mathrm{PH}_{3}\right)_{3}{ }^{{ }^{+}}$where there is little directionality in the bonding of the radical and molecule to the central ion. In these clusters the ion-molecule intermolecular bond length is shorter than the ionradical bond length. In the hemibonded structure for $\left(\mathrm{NH}_{3}\right)_{3}{ }^{{ }^{+}}$, the additional ammonia molecule is hydrogen bonded to one of the ammonia molecules of the central $\left(\mathrm{NH}_{3}{ }^{--}\right.$ $\left.\mathrm{NH}_{3}\right)^{{ }^{+}}$core, while in the case of $\left(\mathrm{H}_{2} \mathrm{O}\right)_{3}{ }^{{ }^{+}}$, the additional water molecule is hydrogen bonded to both water molecules of the $\left(\mathrm{H}_{2} \mathrm{O}--\mathrm{H}_{2} \mathrm{O}\right)^{{ }^{+}}$core. The structures of $(\mathrm{HF})_{3}{ }^{+}$ and $(\mathrm{HCl})_{3}{ }^{{ }^{+}}$are similar to each other with the additional molecules bonded to one of the central molecules. For $\left(\mathrm{PH}_{3}\right)_{3}{ }^{+}$and $\left(\mathrm{H}_{2} \mathrm{~S}\right)_{3}{ }^{{ }^{+}}$the additional molecules are located between the two hemibonded molecules. For these clusters, the hemibond length is longer than the intermolecular bond lengths to the addition molecule with the exception of $\left(\mathrm{PH}_{3}\right)_{3}{ }^{+}$, reflecting the weaker interaction between $\left(\mathrm{PH}_{3}\right)_{3}$ molecules. The relative energies of these clusters are shown in Table 2. Once zero point energy is included, the trend of increasing relative stability of ion-radical isomer with the sequence $\left(\mathrm{NH}_{3}\right)_{3}{ }^{+} \rightarrow\left(\mathrm{H}_{2} \mathrm{O}\right)_{3}{ }^{+} \rightarrow(\mathrm{HF})_{3}{ }^{+}$remains. However, the difference between the computed $\Delta E_{o}$ values is smaller than for the dimers. For the second row hydrides, the hemibonded structure remains the most stable. However, the energy difference between the hemibonded structure and the ion-radical structure is reduced significantly for $(\mathrm{HCl})_{3}{ }^{+}$, and both $\Delta E_{e}$ and $\Delta E_{o}$ are smaller than for $\left(\mathrm{H}_{2} \mathrm{~S}\right)_{3}{ }^{+}$.

For the tetramers, the structures of the ion-radical forms have the radical and neutral 
molecules in a trigonal arrangement around the central ion. $(\mathrm{HF})_{4}{ }^{{ }^{+}}$and $(\mathrm{HCl})_{4}{ }^{{ }^{+}}$are exceptions to this since they have only two hydrogens on the central ion and as a result the tetramers have a chain-like structure. The hemibonded structures all have two molecules arranged around the cationic hemibonded core. These additional molecules can be associated with different ends of the central core, such as in $\left(\mathrm{NH}_{3}\right)_{4}{ }^{+}$and $(\mathrm{HF})_{4}{ }^{+},\left(\mathrm{H}_{2} \mathrm{~S}\right)_{4}{ }^{+}$and $(\mathrm{HCl})_{4}{ }^{+}$, or in the case of $\left(\mathrm{H}_{2} \mathrm{O}\right)_{4}{ }^{{ }^{+}}$one of the water molecules is hydrogen bonded to both water molecules of the core. Again, for the tetramers the ion-radical structure is most stable for the first row hydride cations, and its relative stability compared to the hemibonded structures increases from $\left(\mathrm{NH}_{3}\right)_{4}{ }^{{ }^{+}}$to $(\mathrm{HF})_{4}{ }^{+}$. For the second row hydride cations, the hemibonded isomers are more stable with an increasing relative stability of the hemibonded form on moving across the row.

In order to gain further insight into these trends, and explain why the first row radical cation hydrides favour the ion-radical structures and those for the second row have hemibonded structures we decompose the conversion of the hemibonded isomer to the ion-radical isomer into a number of steps. These steps are illustrated for $\left(\mathrm{H}_{2} \mathrm{O}\right)_{2}{ }^{+}$as follows

$$
\begin{gathered}
{\left[\mathrm{H}_{2} \mathrm{O}--\mathrm{H}_{2} \mathrm{O}\right]^{+} \stackrel{\Delta \mathrm{H}_{1}}{\longrightarrow} \mathrm{H}_{2} \mathrm{O}+\left(\mathrm{H}_{2} \mathrm{O}\right)^{\cdot+} \stackrel{\Delta \mathrm{H}_{2}}{\longrightarrow} \mathrm{H}_{2} \mathrm{O}+\mathrm{OH}^{\cdot}+\mathrm{H}^{+}} \\
\stackrel{\Delta \mathrm{H}_{3}}{\longrightarrow}\left(\mathrm{H}_{3} \mathrm{O}\right)^{+}+\mathrm{OH}^{\cdot} \stackrel{\Delta \mathrm{H}_{4}}{\longrightarrow}\left[\left(\mathrm{H}_{3} \mathrm{O}\right)^{+}--\mathrm{OH}^{\cdot}\right]
\end{gathered}
$$

and a similar sequence of steps can be written for the other clusters. The first step involves breaking of the hemibond to form non-interacting neutral and cationic water molecules. This is followed by dissociation of a proton from the cationic water molecule to give a proton and a $\mathrm{OH}$ radical, again these are considered as noninteracting. This proton then combines with the neutral water molecule, which then forms a complex with the $\mathrm{OH}$ radical.

Table 2 shows the energies of these steps for the different cationic dimers evaluated at the MP2/6-31+G* level. These energies are shown relative to $(\mathrm{HF})_{2}{ }^{{ }^{+}}$, the cluster that most strongly favours the ion-radical structure. For these data, a positive number indicates that for the particular step the cluster favours the hemibonded isomer compared to $(\mathrm{HF})_{2}{ }^{+}$, and similarly a negative number indicates that the ion-radical 
isomer is favoured relative to $(\mathrm{HF})_{2}{ }^{+}$. The total of these energies, $\Delta \mathrm{H}_{\mathrm{T}}=\Delta \mathrm{H} 1+\Delta \mathrm{H} 2$ $+\Delta \mathrm{H} 3+\Delta \mathrm{H} 4$ is also shown. If we first consider $\Delta \mathrm{H}_{\mathrm{T}}$, this is indeed zero for $(\mathrm{HF})_{2}{ }^{+}$ and positive for the other clusters, consistent with the $(\mathrm{HF})_{2}{ }^{+}$cluster most strongly favouring proton transfer relative to hemibonding (Table 1). This value then increases for $\left(\mathrm{H}_{2} \mathrm{O}\right)_{2}{ }^{{ }^{+}}$and $\left(\mathrm{NH}_{3}\right)_{2}{ }^{+}$, with larger increases for $\left(\mathrm{PH}_{3}\right)_{2}{ }^{+}$and $\left(\mathrm{H}_{2} \mathrm{~S}\right)_{2}{ }^{+}$, with the value for $(\mathrm{HCl})_{2}{ }^{+}$a little lower than for $\left(\mathrm{H}_{2} \mathrm{~S}\right)_{2}{ }^{+}$. This generally reflects the trends observed in the computed relative energies of the ion-radical and hemibonded isomers observed for the clusters. It should be noted that an exact match between the values in Table 1 is not expected since these values are computed at a different level of theory.

The individual components of $\Delta \mathrm{H}_{\mathrm{T}}$ can then be assessed to determine which factors influence the change from ion-radical to hemibonded that occurs between the first to second row hydrides. $\Delta \mathrm{H} 1$ reflects the strength of the hemibond, which is shown to be stronger for the first row hydrides cations compared to the second row. The computed bond strengths for the hemibonds on the dimers $\left(\mathrm{NH}_{3}\right)_{2}{ }^{+} \rightarrow(\mathrm{HCl})_{2}{ }^{++}$are computed to be $156.1,178.9,172.2,112.8,123.8$ and $120.3 \mathrm{~kJ} / \mathrm{mol}$, respectively. This shows that the $2 p-2 p$ based hemibond is stronger that the $3 p-3 p$ hemibond. This is counter intuitive since the first row hydrides favour the ion-radical form, indicating that the strength of the hemibond is not the driving force for the preferential formation of the hemibonded isomers. For $\Delta \mathrm{H} 2$, proton-transfer will become increasingly favourable as the molecular cation becomes a stronger Brønsted acid. This step strongly favours proton-transfer in $(\mathrm{HF})_{2}{ }^{\cdot+}$ compared to the other clusters. $\Delta \mathrm{H} 3$ shows that as the molecules become a stronger Brønsted base the ion-radical form will be favoured. This step shows a clear trend that indicates that through the sequences $\left(\mathrm{NH}_{3}\right)_{2}{ }^{+} \rightarrow$ $\left(\mathrm{H}_{2} \mathrm{O}\right)_{2}{ }^{+} \rightarrow(\mathrm{HF})_{2}{ }^{{ }^{+}}$and $\left(\mathrm{PH}_{3}\right)_{2}{ }^{{ }^{+}} \rightarrow\left(\mathrm{H}_{2} \mathrm{~S}\right)_{2}{ }^{{ }^{+}} \rightarrow(\mathrm{HCl})_{2}{ }^{++}$the hemibonded isomer becomes preferred.

\section{Conclusions}

The lowest energy ion-radical and hemibonded structures for the first and second row radical cation hydride clusters with $n=2-4$ have been determined with a basinhopping MP2 approach, with the energies evaluated at the $\operatorname{CCSD}(\mathrm{T}) /$ aug-cc-pVTZ level. The results show that for $\left(\mathrm{NH}_{3}\right)_{\mathrm{n}}{ }^{+},\left(\mathrm{H}_{2} \mathrm{O}\right)_{\mathrm{n}}{ }^{+}$and $(\mathrm{HF})_{\mathrm{n}}{ }^{+}$the ion-radical form is most stable with, in most cases, an increasing relative stability of ion-radical isomer compared to the hemibonded ones. For $\left(\mathrm{PH}_{3}\right)_{\mathrm{n}}{ }^{+},\left(\mathrm{H}_{2} \mathrm{~S}\right)_{\mathrm{n}}{ }^{+}$and $(\mathrm{HCl})_{\mathrm{n}}{ }^{+}$the hemibonded form is most stable, with increasing relative stability compared to the 
ion-radical isomer. This shows that trends observed for dimers remain as the clusters get larger. Decomposing the conversion of the hemibonded structure into the ionradical structure into a several steps, indicates that these trends arise primarily from the relative strengths of the molecules and molecular cations as Brønsted bases and acids, respectively, and the strength of the interaction between the ion and radical in the proton transfer clusters.

\section{Acknowledgements}

We thank the University of Nottingham High Performance Computing facility for providing computer recourses and the Engineering and Physical Sciences Research Council (EPSRC) for funding (Grant No. EP/I012303).

\section{Notes and references}

$\dagger$ Electronic Supplementary Information (ESI) available: Coordinates of the optimized structures. See DOI: 10.1039/b000000x/

${ }^{1}$ B. Kirste, R. W. Alder, R. B. Sessions, M. Bock, H. Kurreck and S. F. Nelsen, J. Am. Chem. Soc., 1985, 107, 2635-2640.

2 P. M. W. Gill and L. Radom, J. Am. Chem. Soc., 1988, 110, 4931-4941.

${ }^{3}$ T. Clark, J. Am. Chem. Soc., 1988, 110, 1672-1678.

${ }^{4}$ E. L. Coitino, A. Lledos, R. Serra, J. Bertran and O. N. Ventura, J. Am. Chem. Soc., 1993, 115, 9121-9126.

${ }^{5}$ M. Sodupe, A. Olivia, and J. Bertran, J. Am. Chem. Soc., 1994, 116, 8249-8258.

${ }^{6}$ M. Sodupe, A. Olivia, and J. Bertran, J. Am. Chem. Soc., 1995, 117, 8416-8421.

${ }^{7}$ S. P. de Visser, L. J. de Koning and N. M. M. Nibbering, J. Phys. Chem., 1995, 99, 15444-15447.

${ }^{8}$ S. P. de Visser, L. J. de Koning and N. M. M. Nibbering, J. Am. Chem. Soc., 1998, 120, 1517-1522. 
${ }^{9}$ T. K. Ghanty and S. K. Ghosh, J. Phys. Chem. A, 2002, 106, 11815-11821.

${ }^{10}$ I. G. Gurtubay, N. D. Drummond, M. D. Towler and R. J. Needs, J. Chem. Phys., 2006, 124, 24318.

${ }^{11}$ R. Joshi, T. K. Ghanty, S. Naumov and T. Mukherjee, J. Phys. Chem. A, 2007, 111, 2362-2367.

${ }^{12}$ A. Kumar, M. Kolaski, H. Myoung Lee and K. S. Kim, J. Phys. Chem. A, 2008, 112, 5502-5508.

${ }^{13}$ P. A. Pieniazek, J. VandeVondele, P. Jungwirth, A. I. Krylov and A. E. Bradforth, J. Phys. Chem. A, 2008, 112, 6159-6170.

${ }^{14}$ Q. Cheng, F. A. Evangelista, A. C. Simmonett, Y. Yamaguchi and H. F. Schaefer III, J. Phys. Chem. A, 2009, 113, 13779-13789.

${ }^{15}$ H. M. Lee and H. Kim, J. Chem. Theory Comput., 2009, 5, 976-981.

${ }^{16}$ H. Kim and H. M. Lee, J. Phys. Chem. A, 2009, 113, 6859-6864.

${ }^{17}$ G. Gardenier M. A. Johnson and A. B. McCoy, J. Phys. Chem. A, 2009, 113, 47724779.

${ }^{18}$ E. Kamarchik, O. Kostko, J. M. Bowman, M. Ahmed and A. I. Krylov, J. Chem. Phys., 2010, 132, 194311.

${ }^{19}$ K. Mizuse, J. L. Kuo and A. Fujii, Chem. Sci., 2011, 2, 868-876.

${ }^{20}$ D. M. Chipman, J. Phys. Chem. A, 2011, 115, 1161-1171.

${ }^{21}$ M. Rapacioli, F. Spiegelman, A. Scemama and A. Mirtschink, J. Chem. Theory Comput., 2011, 7, 44-55.

${ }^{22}$ M. Yamaguchi, J. Phys. Chem. A, 2011, 115, 14620-14628.

${ }^{23}$ H. M. Lee and H. Kim, Theor. Chem. Acc., 2011, 130, 543-548.

${ }^{24}$ A. Golan and M. Ahmed, J. Phys. Chem. Lett., 2012, 3, 458-462. 
${ }^{25}$ M.-K. Tsai, J.-L. Kuo and J.-M. Lu, Phys. Chem. Chem. Phys., 2012, 14, $13402-$ 13408.

${ }^{26}$ P.-R. Pan, Y.-S. Lin, M.-K. Tsai, J.-L. Kuo and J.-D. Chai, Phys. Chem. Chem. Phys., 2012, 14, 10705-10712.

${ }^{27}$ R. Joshi, T. K. Ghanty, T. Mukherjee and S. Naumov, J. Phys. Chem. A, 2012, 116, 11965-11972.

${ }^{28}$ K. Mizuse and A. Fujii, J. Chem. Phys. A, 2013, 117, 929-938.

${ }^{29}$ H. Tachikawa and T. Takada, Chem. Phys., 2013, 415, 76-83.

${ }^{30}$ H. Do and N. A. Besley, J. Phys. Chem. A, 2013, 117, 5385-5391.

${ }^{31}$ D. J. Wales and J. P. K. Doye, J. Phys. Chem. A, 1997, 101, 5111-5116.

${ }^{32}$ Y. Shao, L. Fusti-Molnar, Y. Jung, J. Kussmann, C. Ochsenfeld, S. T. Brown, A. T. B. Gilbert, L. V. Slipchenko,S. V. Levchenko, D. P. O’Neill, R. A. Distasio Jr., R. C. Lochan, T. Wang, G. J. O. Beran, N. A. Besley, J. M., Herbert, C. Y. Lin, T. Van Voorhis, S. H. Chien, A. Sodt, R. P. Steele, V. A. Rassolov, P. E. Maslen, P. P. Korambath, R. D. Adamson, B. Austin, J. Baker, E. F. C. Byrd, H. Dachsel, R. J. Doerksen, A. Dreuw, B. D. Dunietz, A. D. Dutoi, T. R. Furlani, S. R. Gwaltney, A. Heyden, S. Hirata, C.-P. Hsu, G. Kedziora, R. Z. Khalliulin, P. Klunzinger, A. M. Lee, M. S. Lee, W. Liang, I. Lotan, N. Nair, B. Peters, E. I. Proynov, P. A. Pieniazek, Y. M. Rhee, J. Ritchie, E. Rosta, C. D. Sherrill, A. C. Simmonett, J. E. Subotnik, H. L. Woodcock III, W. Zhang, A. T. Bell, A. K. Chakraborty, D. M. Chipman, F. J. Keil, A. Warshel, W. J. Hehre, H. F. Schaefer III, J. Kong, A. I. Krylov, P. M. W. Gill, M. Head-Gordon Phys. Chem. Chem. Phys., 2006, 8, 3172-3191.

${ }^{33}$ H. Do and N. A. Besley, J. Chem. Phys., 2012, 137, 134106.

${ }^{34}$ M. Iwamatsu and Y. Okabe, Chem. Phys. Lett., 2004, 399, 396-400.

${ }^{35}$ MOLPRO, version 2006.1, a package of ab initio programs, H.-J. Werner, P. J. Knowles, R. Lindh, F. R. Manby, M. Schütz, P. Celani, T. Korona, G. Rauhut, R. D. Amos, A. Bernhardsson, A. Berning, D. L. Cooper, M. J. O. Deegan, A. J. Dobbyn, F. Eckert, C. Hampel, G. Hetzer, A. W. Lloyd, S. J. McNicholas, W. Meyer, M. E. 
Mura, A. Nicklass, P. Palmieri, R. Pitzer, U. Schumann, H. Stoll, A. J. Stone, R. Tarroni and $\mathrm{T}$. Thorsteinsson.

${ }^{36}$ A. D. Becke, J. Chem. Phys., 1993, 98, 5648.

${ }^{37}$ P. J. Stephens, F. J. Devlin, C. F. Chabalowski and M. J. Frisch, J. Phys. Chem., 1994, 98, $11623-11627$.

${ }^{38}$ S. Grimme, J. Comput. Chem., 2006, 27, 1787-1799.

39 S. F. Boys, Rev. Mod. Phys. 1960, 32 , 296-299.

${ }^{40}$ A. J. W. Thom, E. J. Sundstrom and M. Head-Gordon, Phys. Chem. Chem. Phys., 2009, 11, 11297-11304. 
Table 1: Relative energies ( $\Delta E=E_{\text {ion }}$-radical $\left.-E_{\text {hemibonded }}\right)$ of the lowest energy ion-radical and hemibonded isomers in $\mathrm{kJ} / \mathrm{mol} . \Delta E_{e}$ - uncorrected energies, $\Delta E_{O}$ energies corrected for zero point energy.

\begin{tabular}{|c|c|c|}
\hline Molecule & $\Delta E_{e}$ & $\Delta E_{o}$ \\
\hline$\left(\mathrm{NH}_{3}\right)_{2}{ }^{++}$ & -21.8 & -26.3 \\
\hline$\left(\mathrm{H}_{2} \mathrm{O}\right)_{2}{ }^{+}$ & -29.6 & -37.6 \\
\hline$(\mathrm{HF})_{2}{ }^{++}$ & -46.4 & -47.0 \\
\hline$\left(\mathrm{PH}_{3}\right)_{2}{ }^{+}$ & +21.9 & +15.9 \\
\hline$\left(\mathrm{H}_{2} \mathrm{~S}\right)_{2}{ }^{++}$ & +96.3 & +91.8 \\
\hline$(\mathrm{HCl})_{2}{ }^{+}$ & +108.5 & +107.4 \\
\hline$\left(\mathrm{NH}_{3}\right)_{3}{ }^{++}$ & -45.7 & -49.0 \\
\hline$\left(\mathrm{H}_{2} \mathrm{O}\right)_{3}{ }^{+}$ & -39.2 & -51.6 \\
\hline$(\mathrm{HF})_{3}{ }^{+^{+}}$ & -57.2 & -57.4 \\
\hline$\left(\mathrm{PH}_{3}\right)_{3}{ }^{++}$ & +10.6 & +9.6 \\
\hline$\left(\mathrm{H}_{2} \mathrm{~S}\right)_{3}{ }^{++}$ & +83.4 & +80.0 \\
\hline$(\mathrm{HCl})_{3}{ }^{+}$ & +58.9 & +55.7 \\
\hline$\left(\mathrm{NH}_{3}\right)_{4} 4^{+}$ & -43.4 & -47.4 \\
\hline$\left(\mathrm{H}_{2} \mathrm{O}\right)_{4}{ }^{+}$ & -43.5 & -53.7 \\
\hline$(\mathrm{HF}) 4^{+^{+}}$ & -57.9 & -58.8 \\
\hline$\left(\mathrm{PH}_{3}\right)_{4}{ }^{++}$ & +8.9 & +6.0 \\
\hline$\left(\mathrm{H}_{2} \mathrm{~S}\right)_{4}{ }^{++}$ & +76.0 & +70.2 \\
\hline$(\mathrm{HCl})_{4}{ }^{+}$ & +77.7 & +77.9 \\
\hline
\end{tabular}


Table 2: Energy changes for the different stages in the conversion of the hemibonded dimer to ion-radical form relative to $(\mathrm{HF})_{2}{ }^{+}$.

\begin{tabular}{|c|c|c|c|c|c|}
\hline Molecule & $\Delta \mathrm{H} 1$ & $\Delta \mathrm{H} 2$ & $\Delta \mathrm{H} 3$ & $\Delta \mathrm{H} 4$ & $\Delta \mathrm{H}_{\mathrm{T}}$ \\
\hline$(\mathrm{HF})_{2}{ }^{+}$ & 0 & 0 & 0 & 0 & 0 \\
\hline$\left(\mathrm{H}_{2} \mathrm{O}\right)_{2}{ }^{+}$ & +6.6 & +279.0 & -222.4 & -46.8 & +14.7 \\
\hline$\left(\mathrm{NH}_{3}\right)_{2}{ }^{+}$ & -16.6 & +493.2 & -407.7 & -54.9 & +14.0 \\
\hline$\left(\mathrm{PH}_{3}\right)_{2}{ }^{+}$ & -59.4 & +414.7 & -330.1 & +14.3 & +39.5 \\
\hline$\left(\mathrm{H}_{2} \mathrm{~S}\right)_{2}{ }^{+}$ & -48.5 & +377.1 & -240.6 & -1.39 & +86.6 \\
\hline$(\mathrm{HCl})_{2}{ }^{+}$ & -52.0 & +183.9 & -72.2 & +14.5 & +74.2 \\
\hline
\end{tabular}




\section{Figure Captions}

Figure 1: Lowest energy ion-radical and hemibonded structures for the dimers. Hemibonds are shown by blue dotted lines. Intermolecular bond lengths are shown in Angström.

Figure 2: Spin densities for $\left(\mathrm{NH}_{3}\right)_{2}{ }^{{ }^{+}}$and $(\mathrm{HCl})_{2}{ }^{+}$clusters with and Mulliken charges for the molecular fragments. Regions of increasingly high spin density are represented by yellow, green and blue.

Figure 3: Molecular orbitals of the ion-radical $\left(\mathrm{H}_{2} \mathrm{O}\right)_{2}{ }^{\cdot+}$ isomer.

Figure 4: Molecular orbitals of the hemibonded $\left(\mathrm{H}_{2} \mathrm{O}\right)_{2}{ }^{{ }^{+}}$isomer.

Figure 5: Lowest energy ion-radical and hemibonded structures for the trimers. Hemibonds are shown by blue dotted lines. Intermolecular bond lengths are shown in Angström.

Figure 6: Lowest energy ion-radical and hemibonded structures for the tetramers. Hemibonds are shown by blue dotted lines. Intermolecular bond lengths are shown in Angström. 
Figure 1: Lowest energy ion-radical and hemibonded structures for the dimers. Hemibonds are shown by blue dotted lines. Intermolecular bond lengths are shown in Angström.

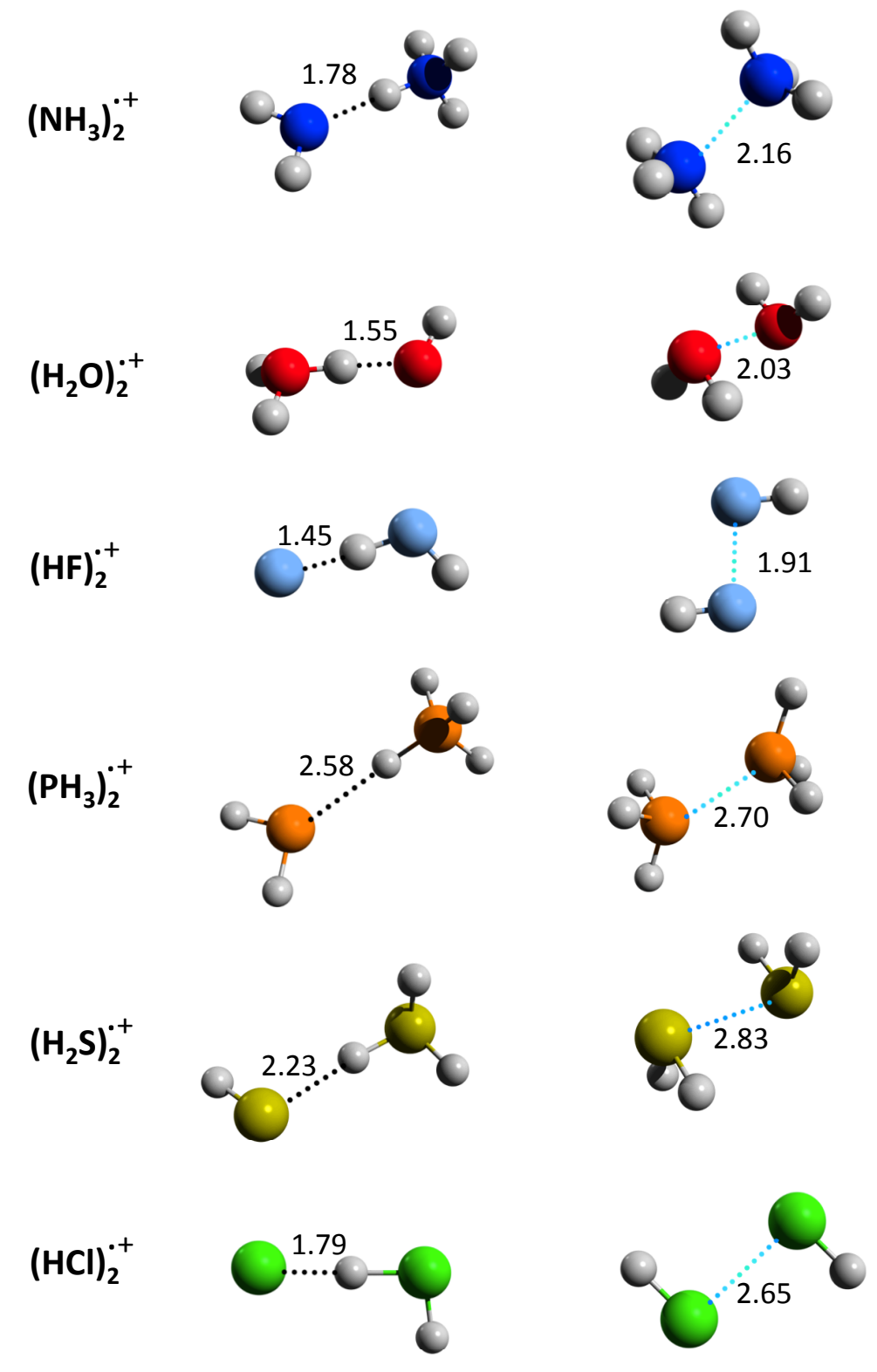


Figure 2: Spin densities for $\left(\mathrm{NH}_{3}\right)_{2}{ }^{{ }^{+}}$and $(\mathrm{HCl})_{2}{ }^{{ }^{+}}$clusters with and Mulliken charges for the molecular fragments. Regions of increasingly high spin density are represented by yellow, green and blue.

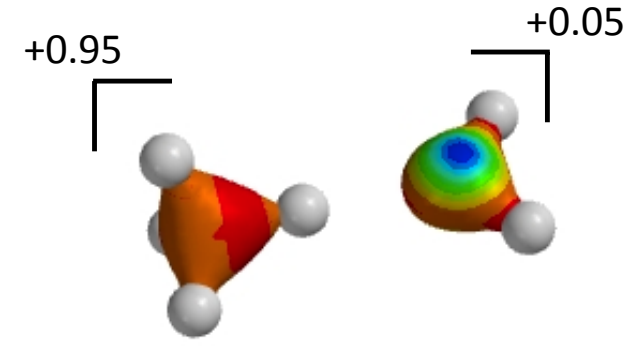

$$
\left(\mathrm{NH}_{3}\right)_{2}^{+}-\text {ion-radical }
$$

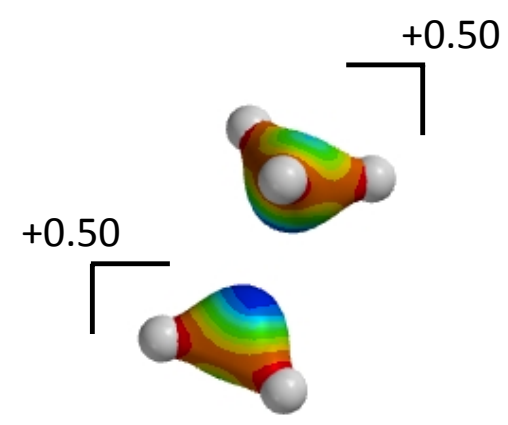

$$
\left(\mathrm{NH}_{3}\right)_{2}^{++} \text {hemibonded }
$$
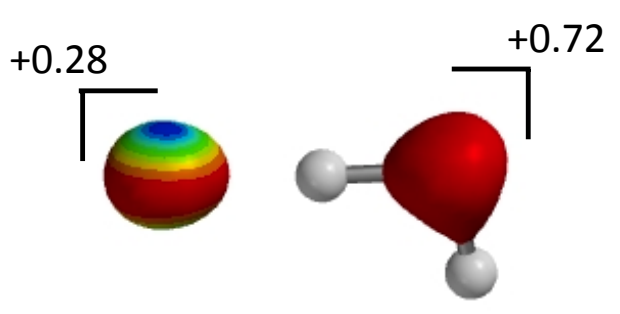

$(\mathrm{HCl})_{2}^{+}-$ion-radical

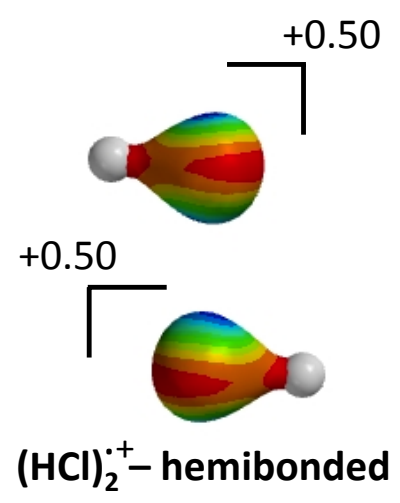


Figure 3: Molecular orbitals of the ion-radical $\left(\mathrm{H}_{2} \mathrm{O}\right)_{2}{ }^{{ }^{+}}$isomer.

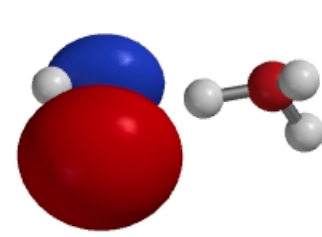

SOMO

LP on $\mathrm{OH}^{\circ}$

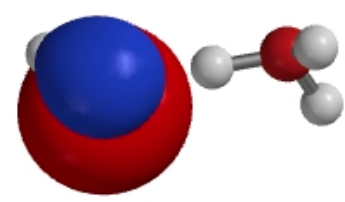

HOMO-3

LP on $\mathrm{OH}^{\circ}$

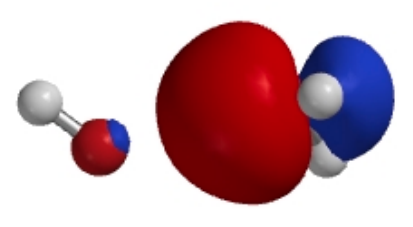

HOMO-1

$\mathrm{OH}$ bond in $\mathrm{H}_{3} \mathrm{O}^{+}$

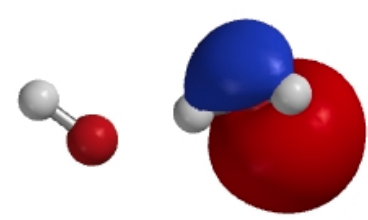

HOMO-4

$\mathrm{OH}$ bond in $\mathrm{H}_{3} \mathrm{O}^{+}$

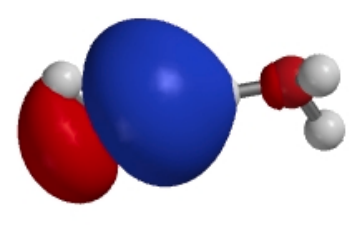

HOMO-2

LP on $\mathrm{OH}^{\circ}$

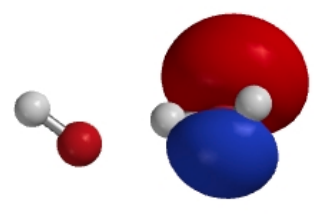

HOMO-5

$\mathrm{LP}$ on $\mathrm{H}_{3} \mathrm{O}^{+}$

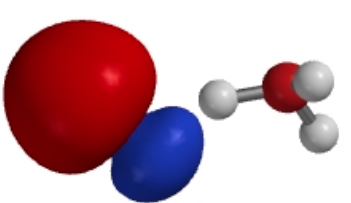

HOMO-6

$\mathrm{OH}$ bond in $\mathrm{OH}^{\circ}$

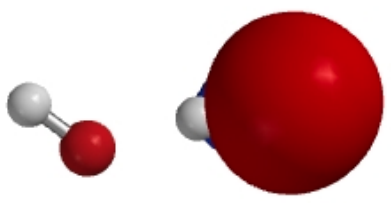

HOMO-7

$\mathrm{OH}$ bond in $\mathrm{H}_{3} \mathrm{O}^{+}$ 
Figure 4: Molecular orbitals of the hemibonded $\left(\mathrm{H}_{2} \mathrm{O}\right)_{2}{ }^{\circ}$ isomer.

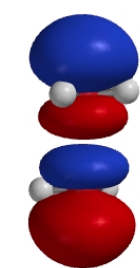

SOMO

0-0 $\sigma^{*}$

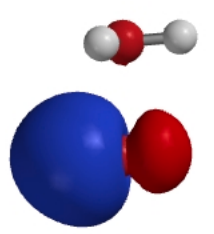

HOMO-3

$\mathrm{OH}$ bond in $\mathrm{H}_{2} \mathrm{O}$

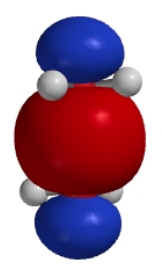

HOMO-1

$0-0 \sigma$
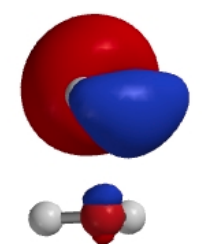

HOMO-4

LP on $\mathrm{H}_{2} \mathrm{O}$

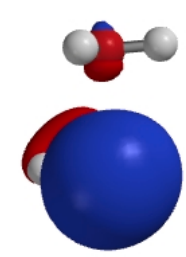

HOMO-2

LP on $\mathrm{H}_{2} \mathrm{O}$

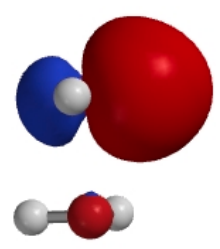

HOMO-5

$\mathrm{OH}$ bond in $\mathrm{H}_{2} \mathrm{O}$

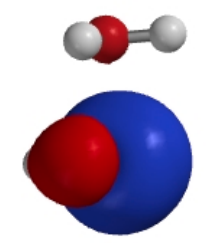

HOMO-6

$\mathrm{OH}$ bond in $\mathrm{H}_{2} \mathrm{O}$

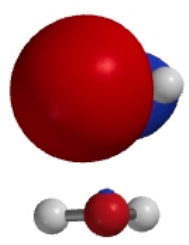

HOMO-7

$\mathrm{OH}$ bond in $\mathrm{H}_{2} \mathrm{O}$ 
Figure 5: Lowest energy ion-radical and hemibonded structures for the trimers. Hemibonds are shown by blue dotted lines. Intermolecular bond lengths are shown in Angström.

$$
\left(\mathrm{NH}_{3}\right)_{3}^{\cdot+}
$$

$\left(\mathrm{H}_{2} \mathrm{O}\right)_{3}^{+}$

$(\mathrm{HF})_{3}^{.+}$

$\left(\mathrm{PH}_{3}\right)_{3}^{+}$
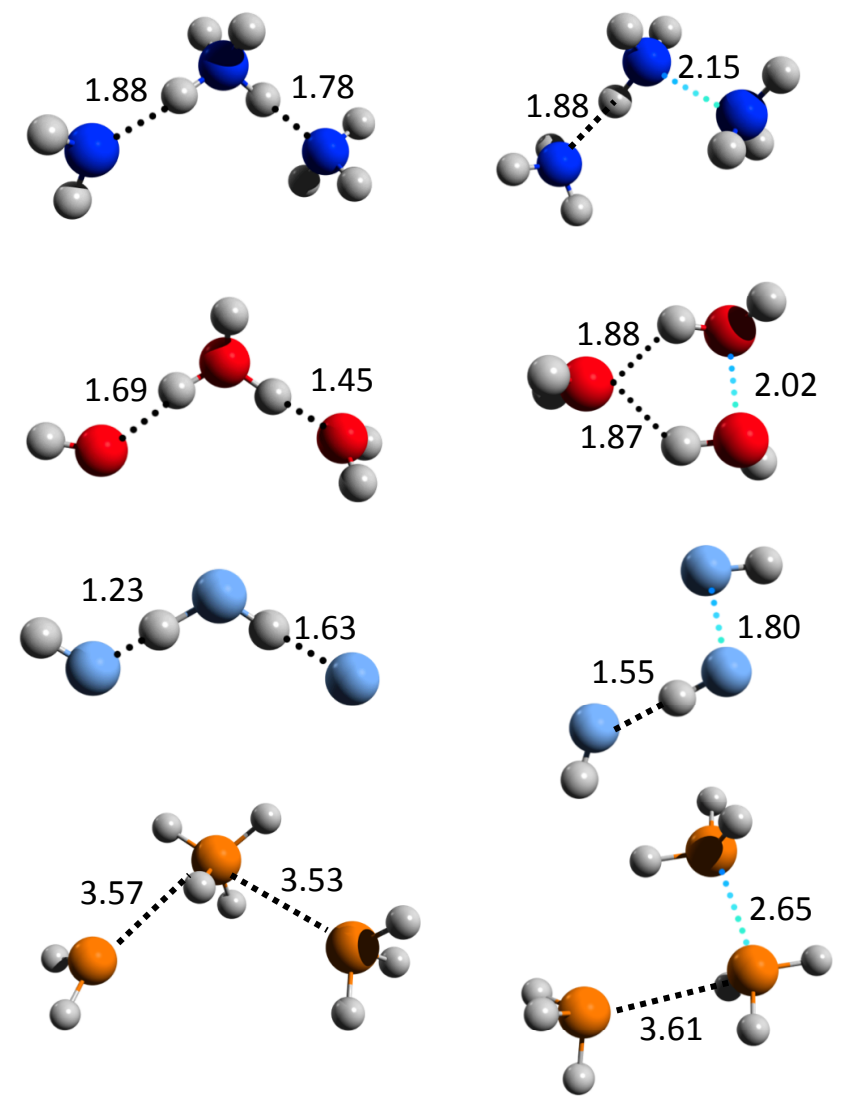

$\left(\mathrm{H}_{2} \mathrm{~S}\right)_{3}^{++}$
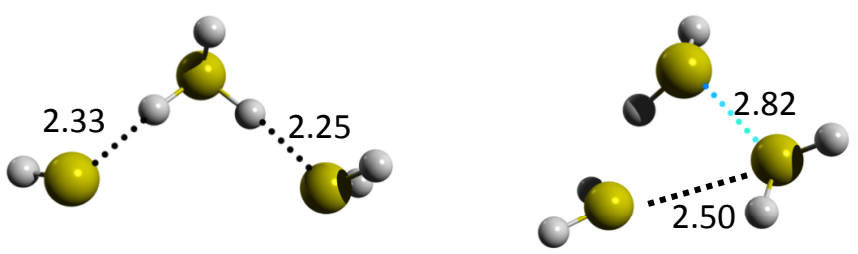

$(\mathrm{HCl})_{3}^{++}$
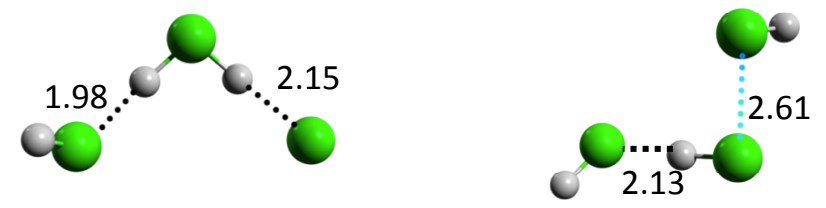
Figure 6: Lowest energy ion-radical and hemibonded structures for the tetramers. Hemibonds are shown by blue dotted lines. Intermolecular bond lengths are shown in Angström.

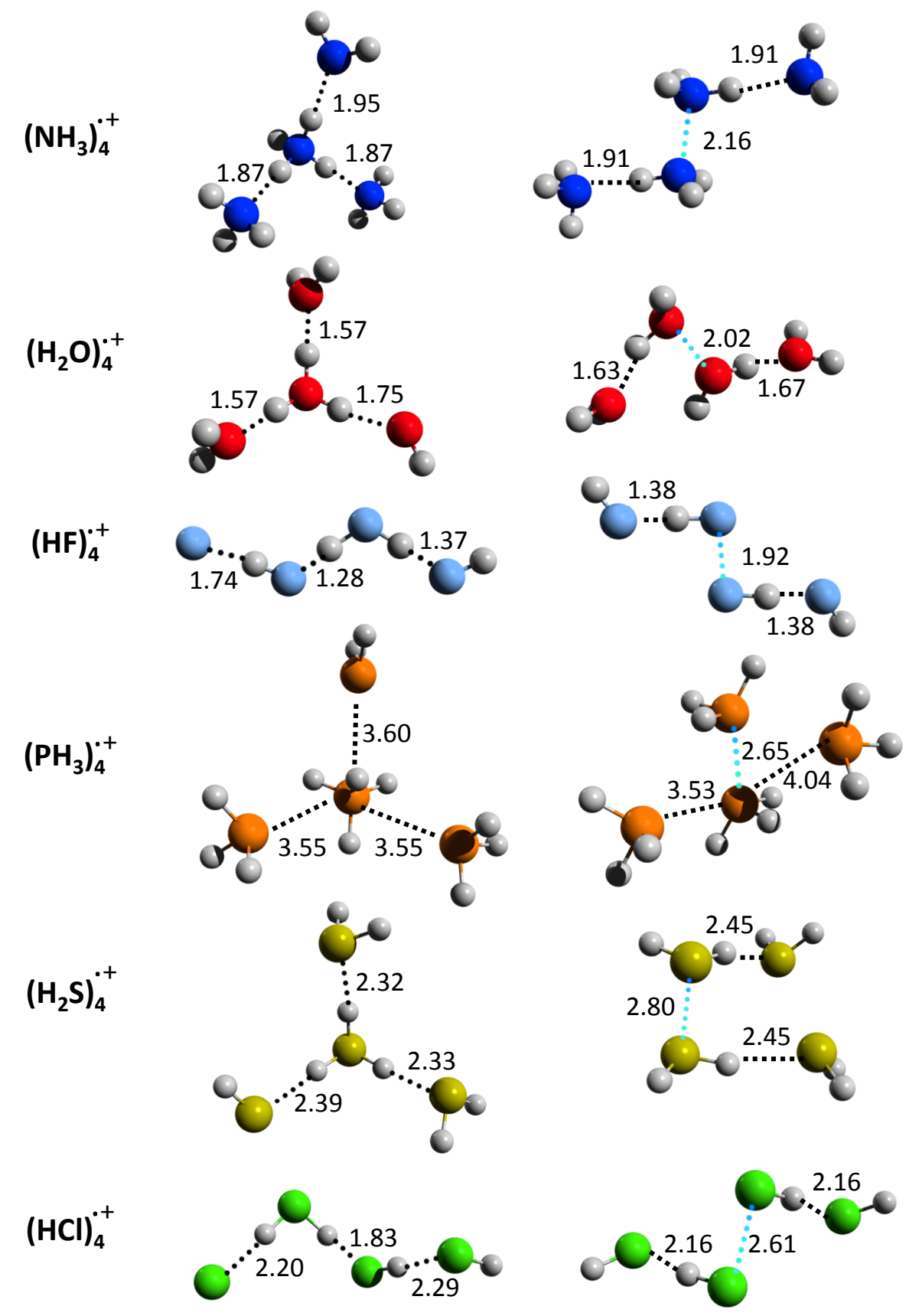




\section{Graphical Abstract}
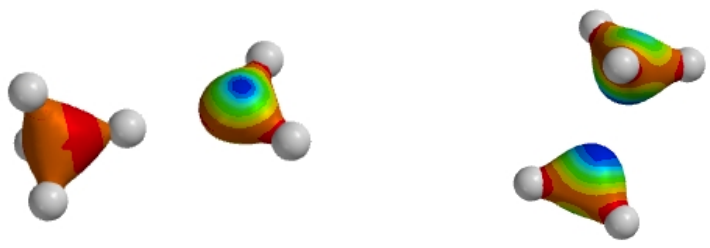

proton transfer vs hemibonding

Basin hopping in conjunction with Møller-Plesset perturbation theory is used to determine the lowest energy ion-radical and hemibonded clusters. 